Faculdade de Ciências Econômicas UFRGS

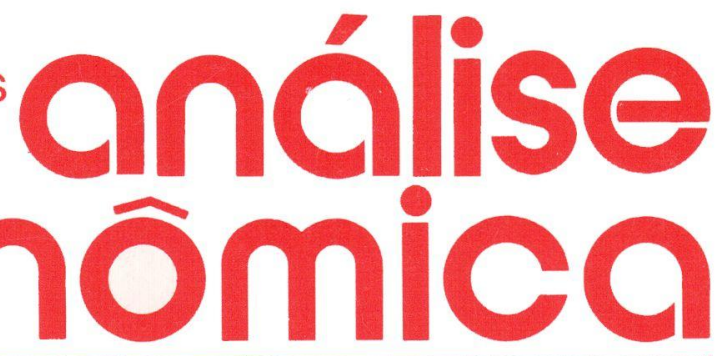

- teoria do balanço de PAGAMENTOS Joáo Luis Tenreiro Barroso

- a IMPORTÂncIa das teorias DE SALÁRIO PARA AS TEORIAS DE INFLAÇÃO Lúcia Maria Góes Moutinho

- os ciclos da economia BRASILEIRA

Vera Beatriz da Silva Oliveira

- SUBSÍDIOS DE PREÇOS AO TRIGO NO BRASIL

Vera Martins da Silva

- A EFICIÊnCIA dA AGRICULtURA GAÚCHA

Juvir Luiz Mattuella

- A economia Regional no BRASIL

Paulo Roberto Haddad

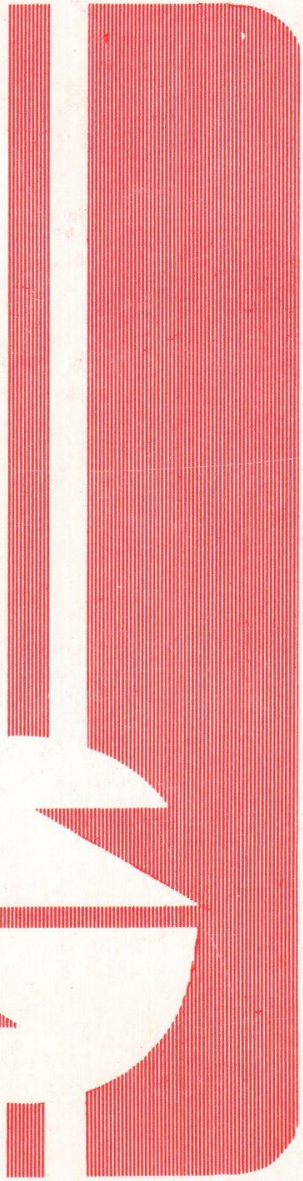


UNIVERSIDADE FEDERAL DO RIO GRANDE DO SUL

Reitor: Prof. Gerhard Jacob

FACULDADE DE CIÊNCIAS ECONÔMICAS

Diretor. Prof. Walter Meucci Nique

CENTRO DE ESTUDOS E PESQUISAS ECONÔMICAS

Diretor: Prof. Reinaldo Ignacio Adams

DEPARTAMENTO DE CIÊNCIAS ECONÔMICAS

Chefe: Profa Oțtlia Beatriz Kroeff Carrion

CURSO DE PÓS-GRADUAÇĀO EM ECONOMIA

Coordenador: Prof. Roberto Camps Moraes

CURSO DE PÓS-GRADUAÇĀO EM ECONOMIA RURAL

Coordenador: Prof. Aray Miguel Feldens

CONSELHO EDITORIAL:

Achyles Barcelos da Costa, Aray Miguel Feldens, Atos Freitas Grawunder, Carlos Augusto Crusius, Ernani Hickmann, João Rogério Sanson, Juvir Luiz Mattuella, Maria Imilda da Costa e Silva, Nali de Jesus de Souza, Nuno Renan Lopes de Figueiredo Pinto, Otília Beatriz Kroeff Carrion, Otto Guilherme Konzen, Paulo Alexandre Spohr, Pedro Cezar Dutra Fonseca, Reinaldo Ignacio Adams, Roberto Camps Moraes, Valter José Stülp, Yeda Rorato Crusius, Edgar Augusto Lanzer (UFSC) e Humberto Vendelino Richeter (UnB)

COMISSĀO EDITORIAL: Atos Freitas Grawunder; Pedro Cezar Dutra Fonseca, Reinaldo Ignacio Adams e Roberto Camps Moraes.

EDITOR: Nali de Jesus de Souza

SECRETARIA: Francisco Carlos Becco dos Santos, Maria Ivone de Mello (normalizaçāo), Vanete Ricacheski (revisão de textos), Wagner Nunes e Zélide Bregaida.

FUNDADOR: Prof. Antônio Carlos Rosa

A Revista ANÁLISE ECONÔMICA publica dois números anuais nos meses de março e novembro. O preço da assinatura, para 1990, é de 7,0 BTNs (o número avulso custa 4 BTNs), a ser pago através de cheque nominal em nome da "Faculdade de Ciências Econômicas/ UFRGS". Aceita-se permuta com revistas congêneres. Aceitam-se, também, livros para elaboração de resenhas ou recensōes.

Toda correspondência, material para publicação, assinaturas e permutas devem ser dirigidos ao seguinte destinatário:

PROF. NALI DE JESUS DE SOUZA

Revista Análise Econômica

Av. João Pessoa, 52 - sala 28

90.040 - PORTO ALEGRE (RS) - BRASIL

Telefone: 25-5844 ramal 34 


\section{A IMPORTÂNCIA DAS TEORIAS DE SALÁRIO PARA AS TEORIAS DE INFLAÇÃO}

Lúcia Maria Góes Moutinho*

\section{APRESENTAÇÃo}

A essência desta discussão sobre inflação e salário é mostrar a importância de uma interpretação do mercado de trabalho, consistente com a realidade empírica no tratamento e controle dessas variáveis macroeconômicas.

Este artigo encontra-se organizado em três partes. Na primeira, colocam-se em destaque as questões a serem examinadas, bem como a respectiva importância e a metodologia utilizada. Na segunda, expöem-se e comparam-se as principais teorias de salário implícitas nas teorias de inflação aqui focalizadas, isto é, neoclấssica, keynesiana e pós-keynesiana. $\mathrm{Na}$ terceira, relacionam-se as teorias de inflação às teorias de salário e, simultaneamente, discutem-se suas validades quando aplicadas a economias desenvolvidas e subdesenvolvidas.

\section{INTRODUÇÃO}

Ao longo do tempo, a inflação tem recebido reiterada atenção, fato que vem acentuando-se cada vez mais nos últimos vinte e cinco anos. O tema é altamente polêmico, tendo gerado, por conseguinte, inúmeras teorias. $O$ assunto é vasto, a literatura é volumosa e, infelizmente, as conclusões definitivas são poucas. Essa diversidade de interpretação resulta do fato de não ter sido possível, até o momento, a

* Professora da Universidade Católica de Pernambuco.

\begin{tabular}{|l|l|l|l|l|}
\hline ANÁLISE ECONÔMICA & ANO 7 & No11 & MARÇO/89 & p.41-61 \\
\hline
\end{tabular}


construção de uma teoria capaz de explicar todas as inflações que vêm ocorrendo nos liversos países através da História, apesar de terse caracterizado como um fenômeno afeto às economias capitalistas, independente de seus graus de desenvolvimento e de estar, quase sempre, acompanhada de altas taxas de desemprego e de capacidade ociosa.

Tem-se verificado alguma incerteza quanto à escolha de uma teoria relevante capaz de explicar o comportamento da taxa de inflação. Esta mesma limitação aplica-se à questão do comportamento dos salários. O problema do economista reside no fato de ter de explicar, em realidades complexas, fenômenos que podem ser medidos com certa precisão, mas que não ocorrem de forma regular. As fontes de inflação diferem, em qualquer tempo, entre palses desenvolvidos ou subdesenvolvidos, entre palses com fortes ou com fracas organizações trabalhistas, entre palses com estruturas de mercado predominantemente oligopolísticas ou com estruturas mais competitivas, entre palses com economias relativamente fechadas ou fortemente inseridas no comércio internacional. O resultado dessa heterogeneidade é a proliferação de teorias alternativas, que se degladiam pela primazia de explicar o comportamento das variáveis aqui focalizadas.

Encontra-se subjacente ao desenvolvimento das teorias sobre inflação a clássica disputa teórica entre o pensamento keynesiano e monetarista, que resultou da polarização quanto às interpretaçōes das fontes de inflaçāo, gerando, conseqüentemente, a divergência quanto às polfiticas indicadas para seu controle. A diferença entre essas correntes de pensamento não se restringe às origens do processo inflacionário, mas inclui julgamento de valor (Barbosa, 1983). Na verdade, o perigo a ser evitado são essas visōes maniqueĺstas. Uns atribuem à inflaçăo, exclusivamente, o aumento da quantidade de moeda em circulação na economia, enquanto outros julgam que a inflação resulta de outros fatores. No entanto, mais modernamente, no cerne das divergências teóricas sobre inflação, localizam-se, além dessas concepções, outras igualmente importantes. Enquanto a teoria estruturalista atribui a inflação ao estrangulamento de setores de oferta, a teoria dos preços administrados, por outro lado, identifica como causa da inflação os choques de oferta monopolista; já a teoria monetarista aceleracionista, explica a autonomia da inflação através do papel das expectativas; sendo que a teoria da inflação autônoma ou inercial explica a autonomia da inflação através do litígio distributivo. Essas teorias, que in- 
terpretam o processo inflacionário, têm sido classificadas em dois grupos: aquelas que buscam determinar as causas primeiras do processo inflacionário - teorias aceleracionistas - e as que procuram identificar as causas da inércia da inflação - teorias sobre a manutenção da inflação. Sendo estas últimas mais recentes do que as primeiras. Observando as concepçōes sobre inflação, acima listadas, podem-se apontar as quatro primeiras como componentes do primeiro grupo, isto é, teorias acelaracionistas, e as demais pertencentes ao segundo (Rego, 1986).

O presente trabalho não pretende se posicionar ao lado de nenhuma dessas correntes interpretativas da inflação, tendo, isto sim, como objetivo principal, o exame de um aspecto que não apenas desperta curiosidade como também é de crucial importância na obtenção de efetivos resultados de políticas antiinflacionárias. Procura-se tratar da problemática da adequação dos modelos teóricos, em que se apóiam as políticas antiinflacionárias, às diferentes realidades. No exame das limitações das teorias de inflação, diversos caminhos foram tomados, porém uma lacuna permaneceu: aquela relativa à investigação da importância das teorias de salário, implícitas nas teorias de inflação a este respeito.

De parágrafos anteriores, infere-se que a inflação resulta de uma multiplicidade de fatores; concluindo-se, ainda, que, quando são consideradas as especificidades das diferentes economias, tais fatores multiplicam-se, estabelecendo o caráter insatisfatório das teorias que se propōem explicá-las. Não se pretende, aqui, esgotar o assunto, mas, expondo alguns modelos de inflação, busca-se tornar explícita a teoria de salário inserida em seu bojo. Efetua-se a análise inicialmente para paises desenvolvidos e, em seguida, para o caso dos palses mais atrasados, tecendo comentários sobre a dificuldade de sua adequação à realidade e sobre as implicações das políticas antiinflacionárias que nelas se apóiam.

Em sintese, a questão que se coloca ế a de verificar-se em que medida os arcabouços teóricos implicitos nas interpretaçōes da inflação podem adequar-se às diferentes economias. A resposta desta indagação será obtida colocando-se as hipóteses que fundamentam os modelos teóricos frente às realidades de economias distintas. A via escolhida, para cumprir esta finalidade, foi o exame das bases teóricas que envolvem os diferentes tratamentos dispensados ao mercado de trabalho, implícitos nos modelos de inflação. A hipótese básica, a ser 
testada é a de que, quanto mais realista for a teoria de salário, implícita na teoria de inflação, mais eficaz serão as políticas antiinflacionárias.

Um primeiro passo para testar a referida hipótese será a exposição das teorias de salário, incluildas nos modelos de inflação que, posteriomente, serão examinadas. Os modelos selecionados prestam-se, razoavelmente, aos fins aqui propostos, tendo em vista que ressaltam o papel dos salários no processo inflacionário, isolando os efeitos do setor financeiro.

\section{TEORIAS DE SALÁRIO}

$\mathrm{Na}$ literatura, é possilvel identificar uma gama de concepçōes sobre os determinantes dos salários e, portanto, das diferentes maneiras de interpretaçāo que têm sido dispensadas ao mercado de trabalho. Todas as escolas de pensamento econômico têm sua própria interpretação sobre a natureza das leis de determinação dos salários. Nenhuma delas, contudo, logra dar conta do problema de maneira satisfatória.

A intenção da presente seção não é revisar criticamente a hitória do pensamento econômico neste aspecto específico. Visa, primordialmente, abordar as principais contribuições ao tema que se mostram importantes para a construção dos modelos de inflação escolhidos, ou seja, as teorias neoclássica, keynesiana e pós-keynesiana de salário.

A teoria neoclássica expōe a sua versão sobre as variáveis econômicas baseada nas condiçōes de pleno emprego e na ênfase analítica em torno dos salários reais, obtendo-se, por conseguinte, consistência com os propósitos expressos pela Lei de Say. Na realidade, os neoclássicos crêem nos mecanismos de mercado como fiéis condutores da normalidade econômica, isto é, representam os chamados segmentos mais liberais do pensamento econômico. Nesta perspectiva, o trabalho é tratado como um bem a mais na economia, e pode ser observado de duas maneiras: sob a ótica do equilíbrio geral Walrasiano e a do equilíbrio parcial.

Em se tratando do equilíbrio geral, o mercado de trabalho não se apresenta desagregado dos demais mercados, conseqüentemente suas hipóteses não são explicitadas. Neste contexto, o salário é um preço relativo como os preços dos demais bens da economia. Dito de 
outro modo, o salário real nada mais é do que uma relação entre preços: preço do trabalho (o salário nominal) e preço de outros bens. Neste modelo, o salário é determinado de forma simultânea com os demais preços (Ehremberg, 1983).

$O$ enfoque do mercado de trabalho constitui o cerne da versāo macroeconômica neoclássica, que retira da microeconomia Marshaliana os postulados básicos deste mercado. Aqui, é visto como um mercado qualquer que, no entanto, funciona à parte, não integrado ao sistema e, conseqüentemente, inclui explicitamente suas hipóteses: (i) as firmas sāo maximizadoras de lucro; (ii) as firmas combinam capital e trabalho em qualquer proporção; (iii) as firmas são tomadoras de preços, pois participam de um mercado concorrencial (Macedo, 1982).

Este mercado é entendido corno o local onde se procura equilibrar os interesses conflitantes dos empresários e trabalhadores. Os primeiros se dispõem a comprar, e os demais a vender sua força de trabalho, portanto é um mercado onde há oferta e demanda, que serão a seguir definidos (Macedo, 1982).

A oferta de trabalho é expressa por uma curva ascendente, ou seja, quantidades de trabalho e salários reais são diretamente proporcionais. Nela, encontra-se implícito o conceito de "desutilidade marginal do trabalho", que encerra a igualdade entre utilidade do salário e desutilidade de um determinado volume de trabalho.

A idéia é que o trabalhador oferece mais trabalho até o ponto em que a satisfação obtida, através do salário que recebe pelo acréscimo do trabalho oferecido, seja maior ou igual à desutilidade do esforço despreendido. Em resumo, os pontos sobre a curva de oferta de trabalho são "locus" de equilíbrio, que ensejam a igualdade entre a desutilidade marginal do trabalho e o salário real.

Da condição de maximização da firma individual, em regime de concorrência perfeita, origina-se a curva de demanda por força de trabalho. A referida condição pode ser representada por P.PmgL $=W$, isto é, o preço do bem final, multiplicado pela produtividade marginal do trabalho. A PmgL corresponde ao salário monetário, W. Portanto, a firma maximizadora de lucro e aceitadora de preços demandará força de trabalho até igualar o valor da produtividade marginal do trabalho, P.PmgL, ao salário nominal $W$. Isto pode ser reescrito da seguinte maneira, $P m g L=W / P$, o que quer dizer que os trabalhadores são pagos pela produtividade marginal do trabalho.

Neste quadro, nivel de emprego e produtividade marginal do tra- 
balho são inversamente proporcionais e, portanto, a curva de demanda por força de trabalho tem inclinação negativa. A soma horizontal das curvas de demanda individuais resulta na curva de demanda por trabalho de toda a economia.

A igualdade entre as curvas de mercado, oferta agregada de trabalho e demanda agregada de trabalho identificam o salário real de equilíbrio que, tendo como suporte a hipótese da flexibilidade de salários e preços, garante o pleno emprego, comprovando a existência de uma forte crença na estabilidade desse equilibrio.

Em sintese, nesta ótica, a oferta de trabalho está baseada: (i) na necessidade de alguma compensação pelo sacrifício que o trabalho representa para o trabalhador; (ii) na busca da maximização da satisfação do trabalhador; (iii) na satisfação do indivíduo que está relacionada ao lazer e à capacidade de compra de sua renda. Por outro lado, a demanda por trabalho depende: (i) da contribuição do último trabaIhador contratado para a produção; (ii) do salário monetário que deve ser pago ao trabalhador; (iii) do preço que as firmas recebem pelas vendas dos produtos (Macedo, 1982).

A análise keynesiana dos salários difere substancialmente daquela apresentada nos parágrafos acima. Na verdade, ela constitui uma crítica às proposições neoclássicas, à medida que as classifica como inadequadas, fato que se verifica quando são relacionadas às características básicas de uma economia monetária moderna. Keynes destrói o mercado de trabalho neoclássico e, conseqüentemente, a teoria de salário nele fundamentada (Keynes, 1982).

A oposição centra-se nas definições de demanda e de oferta agregadas de trabalho (Maddock \& Carter, 1982): No primeiro caso, a crítica consubstancia-se no fato de os neoclássicos terem confundido os conceitos de demanda agregada de trabalho e de condição de equilíbrio da firma. Este aspecto constitui uma das mais substanciais contribuiçōes de Keynes, tendo em vista que inverte toda a análise macroeconômica do emprego, inclusive do ponto de vista das decisōes políticas. Para Keynes, o nivel de atividade e de emprego é determinado pelo nivel esperado da demanda efetiva empresarial. Assim, as alteraçōes no emprego estão sujeitas às mudanças nos parâmetros que alicerçam a demanda agregada. Conseqüentemente, para que os salários nominais possam afetar o nivel de emprego, necessariamente, teria que ser alterado no curto prazo pelo menos um dos parâmetros dessa demanda: propensão marginal a consumir, eficiência marginal 
do capital e taxas de juro, que são hipoteticamente consideradas invariáveis na análise microeconômica, desenvolvida pelos neoclássicos e que não pode ser sustentata sob a ótica macroeconômica (Silva, 1978).

Relativamente ao aspecto crítico da função de oferta de trabalho, a análise keynesiana respalda-se em dois pontos importantes, que contrariam o esquema teórico neoclássico. Um deles é o aspecto institucional, presente na determinação do salário nominal. O outro referese ao próprio comportamento do trabalhador no mercado de trabalho. Segundo Keynes, a estabilidade econômica não depende exclusivamente das forças automáticas dos mecanismos de preços, isto é, ele mostru-se descrente de que, da negociação entre empresários e trabalhadores, resultasse a determinação do salário real e que a oferta de trabalho fosse por este último determinada. Aliado ao próprio comportamento do trabalhador procurou mostrar que eles negociam com base em uma taxa de salário nominal, estando fora de seu alcance a determinação do salário real que depende, por sua vez, das diversas forças que comandam a demanda agregada. Isto pode ser descrito da seguinte maneira: uma variação para baixo no salário nominal deixaria os trabalhadores inconformados o suficiente para que alguns se retirassem do mercado. Por outro lado, um acréscimo nos preços, dado o salário nominal, não faria com que os trabalhadores abandonassem os seus postos de trabalho. Assim somente no primeiro caso, a oferta reagiria, fato este que comprova a sensibilidade a valores nominais $e$ não a valores reais, como propuseram os neoclássicos. Em resumo, Keynes não concorda com os neoclássicos quanto ao fato de os trabalhadores não sofrerem de "ilusão monetária" (Keynes, 1982).

Além disso, a análise realista do mercado de trabalho, das economias modernas, não poderia excluir uma de suas mais importantes instituições: os contratos de trabalho, que predominam neste contexto e que se apresentam importantes devido às características de incerteza e de preferência pela liquidez, vinculadas ao investimento, um componente da demanda agregada; noção introduzida na teoria macroeconômica por Keynes. $O$ aspecto relevante a ser extraído dessas considerações é que, na análise macroeconômica, os agentes econômicos passam a ter história, o que contrasta frontalmente com a análise neoclássica, onde o passado e o futuro não afetam as decisões tomadas no presente (Silva, 1978).

Como conseqüência desses pontos de vista divergentes, as poli- 
ticas macroeconômicas indicadas através de cada corrente teórica tomam rumos diametralmente opostos. Os cortes de salários, sugeridos pelos neoclássicos, para combater o desemprego deixam de ter sentido na análise keynesiana, tendo em vista que esta última ampliou a perspectiva do enfoque dos salários. Enquanto os neoclássicos atrelaram tais políticas e fenômenos estritamente monetários, o reconhecimento de uma possível influência da demanda agregada trouxe o problema para uma posição de destaque na perspectiva keynesiana.

Apesar dos novos elementos introduzidos na análise dos salários e das objeções dirigidas ao enfoque neoclássico, o trabalho de Keynes deixa transparecer uma certa dificuldade no tratamento dos salários à medida que não desvincula de seu esquema teórico alguns resquícios neoclássicos, como por exemplo, o do postulado que embasa a função. demanda de trabalho, que iguala a produtividade marginal ao salário real, compartilhando da tese segundo a qual a indústria trabalha normalmente sujeita a rendimentos decrescentes no curto prazo (Keynes, 1982).

Em total oposição ao modelo neoclássico e, parcialmente à teoria keynesiana, à medida em que esta última não apresenta firmeza em suas objeções à demanda neoclássica por trabalho, surgem os modelos pós-keynesianos. Estes modelos alternativos garantem que nem a oferta e nem a demanda por trabalho dependem do salário real. Nestes modelos pós-keynesianos, o mercado de trabalho não constitui um mercado verdadeiro, pois não possui aquele sentido comum de estabelecer o equilíbrio. A demanda por trabalho pode ser relacionada com o nivel de produção planejado pelas firmas, sem apresentar qualquer vinculação com a teoria da produtividade marginal. Ela depende do nivel de atividade econômica agregada, e a oferta de trabalho depende de fatores democráficos e sócio-culturais. Assim, a determinação do salário e do emprego são dois processos distintos (Appelbaum, 1979).

A demanda por trabalho, nesta ótica, negando o enfoque tradicional, não apresenta traços de homogeneidade; admite-se a existência de vários mercados de trabalho, nos quais as regras de admissão e dispensa não respondem simplesmente às variações nos salários. Por outro lado, a oferta de trabalho fundamenta-se na existência de inúmeros submercados, onde os trabalhadores competem pela disponibilidade de emprego, e onde há, sobretudo, diferenciaçōes nos salários, nas 
condiçōes de trabalho e nas oportunidades de ascensão, de acordo com o tipo da firma contratante.

Essa caracterização da oferta de trabalho apresenta-se mais realista, tendo em vista que considera a heterogeneidade da mão-de-obra e uma estrutura imperfeita de mercado, composta por firmas de tamanho diverso e com diferentes graus de oligopolização, aspectos não incluídos nos enfoques neoclássicos, anteriormente apresentados. Nos setores mais oligopolizados e de tecnologia sofisticada, o salário é alto, o emprego é mais estável e a organização sindical é potente. Por outro lado, nas empresas de setores não oligopolizados e de tecnologia arcaica os salários são baixos, os empregos são instáveis e a organização sindical é inexpressiva.

Em síntese, trata-se de um enfoque muito mas receptivo das características das diferentes economias, à medida que permite a consideração dos vários determinantes da dinâmica dos salários, que variam de acordo com as circunstâncias e a localização geográfica. Estes determinantes podem ser classificados em três grupos. Um primeiro conjunto reúne os aspectos culturais, hábitos, convenções e normas éticas. O segundo é constituído pelas instituiçōes que regulam as negociações, como por exemplo, as formas de organização de empresas e de trabalhadores e as regras tácitas e legais vigentes, implícitas no jogo de forças. Finalmente, o terceiro conjunto engloba a natureza do regime político, a orientação do Estado e das políticas públicas, fatores que se apresentam atualmente relevates (Frenkel, 1986).

\section{TEORIAS DE INFLAÇÃO E TEORIAS DE SALÁRIO}

Neste tópico, pretende-se expor os modelos de inflação escolhidos, tornando explícita a teoria de salário e guardada em seu bojo. Inicialmente, examina-se o caso dos países desenvolvidos e, em seguida, o caso dos países subdesenvolvidos, em especial o brasileiro, tecendo comentários sobre sua fidelidade à realidade empírica.

\subsection{O Caso de Economias Desenvolvidas}

Um dos prinaeiros trabalhos que relacionam a dinâmica dos preços à dinâmica dos salários foi de autoria de Fisher, em 1926 (Hudson, 
1983). Mais recentemente, em 1958, um trabalho econométrico baseado em dados empíricos do Reino Unido, para o período (1962/1957), desenvolvido por A.W. Phillips, mostrou haver uma relação inversa, não linear, entre desemprego e taxa de variação dos salários nominais. $O$ pressuposto teórico deste trabalho é o de que, havendo excesso de demanda em relação à oferta de qualquer bem, o seu preço se eleva; assim, o excesso de demanda de trabalho elevaria os salários nominais (Hudson, 1983).

Em 1960, R.G. Lipsey teorizou esta relação, que ficou conhecida como "curva de Phillips". Através de um estudo centrado no mercado de trabalho, ele confirmou a constatação de Phillips: havia um "tradeoff" entre inflação e desemprego. Lipsey verificou que o preço do trabalho é determinado pelo mercado e este, por sua vez, constituía fonte de inflação, tendo em vista sua importância na determinação dos custos de produçāo. Nesta perspectiva, taxas de desemprego menores podiam ser obtidas através de políticas expansionistas somente às custas de maiores salários e, conseqüentemente, às custas de maiores preços, formando assim o "trade-off".

A curva de Phillips popularizou-se em decorrência desse "tradeoff", sendo absorvida pela teoria de inflação de economias desenvolvidas e requisitada tanto pelos modelos de inflação de demanda, como pelos modelos de inflação de custo, eliminando divergências na interpretação keynesiana da inflação, suscitadas no final da década de 50 (Rego, 1986). Apesar disso, a análise neoclássica do mercado de trabalho, discutida na seção anterior, encontra-se na sua base teórica, e, conseqüentemente, transmite-Ihe suas limitaçōes. Um exemplo evidente desse tipo de limitação, que o modelo de Lipsey inclui, refere-se à crença da estabilidade da relação taxa de salários/desemprego ou preço/desemprego. Neste esquema teórico, a instabilidade econômica inevitavelmente aconteceria somente se o governo interferisse através de suas políticas, objetivando manter um nivel de desemprego diferente daquele representado pela "taxa natural", isto é, a taxa de pleno emprego da economia (Trevithick, 1979).

Um detalhe interessante, nesta teorização é que o estigma do desemprego parece não ter sido afugentado por seus adeptos. Eles reconheciam a existência do "desemprego voluntário" e do desemprego friccional, advindo da própria conceituação da curva de oferta de trabalho. $O$ primeiro tipo de desemprego corresponde àquelas pessoas que não se habilitariam a ingressar no mercado de trabalho por achar 
inadequada a remuneração equivalente à sua produtividade marginal. $O$ segundo caso refere-se às imperfeiçōes de ajustamento que impedem um estado de contínuo pleno emprego (Macedo, 1982).

Solow e Samuelson construíram uma curva de Phillips para os Estados Unidos, posteriormente a de Lipsey, que foi amplamente aceita nos meios acadêmicos, apesar de relacionar variação de preços, e não a taxa de crescimento dos salários, ao desemprego. Essa curva corresponderia àquela de Phillips e Lipsey, à diferença do acréscimo da produtividade, se fosse admitida a hipótese de que as variaçōes salariais são imediatamente repassadas para os preços, tendo em vista serem estas variaçōes o caminho através do qual o excesso de demanda afeta os preços (Hudson, 1983). A razão principal para se aceitar esta construção era a de que, aparentemente, ela se coadunava com os fatos. A curva de Phillips original, estimada com base em dados de quase um século, inclinava-se negativamente e as taxas de inflação e desemprego dos Estados Unidos também apresentavam o mesmo comportamento. Neste parágrafo, é importante que se chame atenção para a necessidade da inclusão, por parte de Solow e Samuelson, na sua teorização sobre inflação, da hipótese da concorrência perfeita já admitida na teoria de salário por eles considerada.

A mudança relevante nas idéias relativamente ao estudo da inflação deu-se ao final da década de sessenta, quando a curva de Phillips apresentava deslocamentos, tanto a dos Estados Unidos como a do Reino Unido (Ehremberg e Smith, 1983). Nessa ocasião, e mesmo um pouco antes, as atençōes voltavam-se para o papel das expectativas de inflação no processo das negociaçōes salariais, e para o aperfeiçoamento do critério do excesso de demanda como medida do desemprego. Estas foram tentativas de usar a curva de Phillips como instrumento útil de política econômica e de buscar uma explicação para a manutenção da taxa de inflação a partir do modelo das expectativas. A primeira delas envolveu a reconstrução da estrutura teórica de Lipsey, que ficou conhecida como "curva de Phillips com expectativas ampliadas" e que constitui a versão aceleracionista da curva de Phillips.

$\mathrm{O}$ argumento foi apresentado originalmente por Milton Friedman (Hudson, 1983). Segundo ele, a taxa de salário nominal não era adequada ao modelo de Phillips e Lipsey, mas a taxa de salário real, tendo em vista que os contratos de trabalho eram de longo prazo. Com isso, Friedman inseriu na discussão sobre a curva de Phillips uma versão moneratista, como reação ao modelo keynesiano, embora o mo- 
delo de Lipsey utilizasse o modelo neoclássico parcial do mercado de trabalho. $\mathrm{O}$ salário monetário era a variável mais importante como na teoria keynesiana dos salários.

Com a mudança na maneira de introduzir o salário no modelo de inflação, mais um ponto de desacordo é colocado entre os grupos de teoristas keynesianos e monetaristas: a direção causal entre as variáveis preços e salários. Sabe-se que os salários afetam os preços no modelo keynesiano e que o contrário acontece no esquema neoclássico (Hudson, 1983). Este aspecto revela, mais uma vez, que a escolha da teoria de salário encontra-se na base da discussão sobre inflação e que as hipóteses das construçōes teóricas dos salários refletem-se, claramente, nas conclusōes resultantes das teorias de inflação e das políticas que nestas últimas se respaldam. Embora monetaristas e keynesianós concordassem quanto à necessidade de se administrar a demanda, restringindo-a em curtos períodos para conter a inflação, divergiam quanto às medidas políticas utilizadas para este fim. Os primeiros indicavam a política monetária como a mais adequada, enquanto os keynesianos, em oposição, aderiam às medidas fiscais (Rego, 1986).

Os monetaristas "friedmanianos" aderiram ao modelo das expectativas adaptadas, que acrescenta à "curva de Phillips" um outro componente, além da intensidade do excesso de demanda, as expectativas de inflação, através de um processo sugerido por Solow em 1969 (Hudson, 1983). As expectativas adaptadas constituem-se em uma espécie de processo de aprendizado dos agentes econômicos, baseadas em dois elementos: expectativas futuras, orientadas pela média ponderada das taxas de inflação, efetivamente registradas nos períodos passados recentes, e um percentual de correção correspondente ao erro da inflação passada recente. Com relação à intensidade do excesso de demanda, elemento único do modelo tradicional de Phillips, passou a ser normalmente medido pelo hiato do produto, e como ele é considerado mínimo, a inflação acaba tendo como fator determinante principal as expectativas, que explicam o caráter inercial da inflação, isto é, manutenção dos patamares da inflação passada (Rego, 1986). Novamente nesta etapa, merece que seja chamada a atenção para a influência do modelo de salário incluído neste enfoque de inflação e suas conseqüências. $O$ aspecto a minimização do hiato do produto origina-se das proposiçôes neoclássicas do mercado de trabalho que, de acordo com suas hipóteses, levam a crer na existência de pleno emprego. 
Outra forma de explicar o processo de formação de expectativas foi sugerida por Muth, em 1961, a nível microeconômico e, posteriormente, foi expandida para toda a economia por Lucas e Sargent, que se denominou de "expectativas racionais" (Hudson, 1983). Ele foi adotado pelos monetaristas "puros" em seus modelos de inflação. Nesta versão, dois componentes explicam a inflação: a taxa de inflação racionalmente prevista e a taxa esperada de crescimento da oferta monetária. O primeiro componente baseia-se no principio da racionalidade na formação das expectativas, segundo o qual os individuos coletam, manipulam e usam de maneira inteligente (racional) as informações dos efeitos plenos, instantâneos e antecipados das políticas econômicas, resultando em uma perfeita previsão. Neste modelo, a economia é considerada como funcionando realmente de acordo com a teoria neoclássica do equilíbrio geral e, nesta expectativa, o salário é um preço relativo, conforme apresentado na seção anterior. Ele baseia-se no mecanismo otimizador do indivíduo, hipótese do modelo neoclássico de salários.

As maneiras divergentes de interpretar o processo de formação das expectativas conduziram à distinção entre os enfoques de curto e longo prazo da inflação, trazendo uma série de conseqüência relativamente à análise da potencialidade da política econômica (Lasa).

A esse respeito, Friedman observou que, após uma expansão da demanda agregada e reduçāo do desemprego, as expectativas, ao se ajustarem, deslocam, para cima a curva de Phillips.

A título de ilustração, suponha-se que o governo tenha considerado a "taxa natural" de desemprego muito elevada, optando por uma política monetária expansionista, a fim de diminuir a taxa de juro, aumentar o investimento e a demanda, diminuindo, por conseguinte o desemprego. Evidentemente, nesta ótica, este seria o primeiro impacto; porém, o governo não alcançaria o seu intento, tendo em vista o funcionamento do mercado de trabalho, que reagiria da seguinte maneira (Maddock e Carter, 1982): com a economia funcionando a pleno emprego de sua capacidade produtiva, quando a demanda aumenta, como resultado da política, os empresários só conseguiam contratar mais trabalhadores oferecendo-Ihes maiores salários. Isto, por sua vez, representa custos em elevação. Acrescente-se, ainda, que, neste esquema, as empresas defrontam-se com rendimentos decrescentes no curto prazo.

O efeito final do aumento de demanda, frente a uma oferta per- 
feitamente inelástica traduz-se em preços e salários nominais mais elevados, mas salário real, produção e emprego invariáveis, tendo em vista que os trabalhadores retraem a oferta de força de trabalho no longo prazo, quando percebem as perdas reais de seus salários. Isto faz com que a taxa efetiva de desemprego retorne à "taxa natural". O ajustamento das expectativas, por certo, elevaria os custos da inflação, ao se procurar manter um nivel mais baixo de desemprego, porém não haveria um "trade-off" entre inflação e desemprego no longo prazo, o que significa uma curva de Phillips de longo prazo vertical e, conseqüentemente, uma política de expansão de demanda impotente para reduzir o desemprego em longos períodos. Com respeito ao curto prazo, contudo, as políticas de expansāo da demanda provocariam a redução do desemprego até que a taxa esperada de inflação se ajuste à taxa de inflação corrente. Isto quer dizer que o público leva algum tempo para se dar conta da taxa de inflaçāo e, quando percebe, o governo já poderia tê-la elevado novamente. Todavia, não se admitia que o público não se conscientizasse, com o correr do tempo, de que a inflação vinha se acelerando. Desta maneira, seria razoável argumentar que a aceleração da taxa de inflação seja um processo crescente, mesmo assim, o público finalmente se aperceberia do que estava acontecendo. Assim, nesta perspectiva dos monetaristas friedmanianos, mesmo que seja possivel afetar a taxa de desemprego, através de uma política de aceleração de demanda agregada de curto prazo, isso não seria possivel no longo prazo.

No entanto, os monetaristas "puros" não acreditam na potencialidade da política governamental nem mesmo no curto prazo, tendo em vista que consideram uma curva de Phillips vertical também neste intervalo de tempo, excetuando-se no caso em que fosse amplamente anunciada e posta em prática, sem causar surpresa, uma política de contração da expansão dos meios de pagamentos (Rego, 1986).

A comparação entre os modelos de inflação aqui discutidos demonstra uma série de modificações pelas quais passou a relação entre inflação e desemprego de autoria de Phillips e Lipsey, amplamente utilizadas na explicação da inflação em países desenvolvidos. Entre outros, o motivo principal dessas transformações foi a necessidade de aproximá-los aos fatos. Essas tentativas frustraram-se em relação ao objetivo almejado. Um aspecto que aqui merece especial atenção e, que foi examinado, refere-se à análise dos salários que estes modelos de inflação incluem. Em geral, os modelos de salário subjacentes são 
estáticos, e, naturalmente, transferem este caráter ao modelo de inflação. Torna-se necessário lembrar que a inflação é um fenômeno essencialmete dinâmico e que os salários não fogem a essa regra. As evidências deram sinais desta inconsistência através da instabilidade da curva de Phillips original.

Uma parte das hipóteses irrealistas em que se alicerçava a teoria dos salários e, por extensão as teorias de inflação, como, por exemplo, a competitividade nos mercados, o apelo a uma ordem natural e a racionalidade constituíram o centro das preocupaçōes dos teóricos. Porém, mesmo que tenham sido introduzidas modificações substanciais, como, entre outras, o fato de se admitir a interfêrencia do governo no mercado de trabalho, este último continuou a não receber um tratamento adequado, tendo em vista que permaneceu sendo encarado como um segmento independente do resto da economia (Frenkel, 1986). Além dessas dificuldades, existem outras de ordem prática não satisfatoriamente resolvidas, como os problemas de agregação da curva de Phillips da medida das expectativas a elas associadas (Hudson, 1983), e da explicação da dinâmica dos salários (Frenkel, 1986), comprovando a fragilidade do instrumento.

Esta fragilidade não somente se acentua como torna proibitiva a sua aplicação em economias menos desenvolvidas, tendo em vista que os vários determinantes da dinâmica dos salários e, conseqüentemente, dos preços, variam de acordo com as circunstâncias, localização geográfica e um conjunto de caracteristicas próprias de cada sociedade.

\subsection{Inflação e Salários em Economias Subdesenvolvidas}

Indıstintamente, tem-se utilizado a curva de Phillips para o tratamento dos fenômenos que ocorrem tanto' em economias desenvolvidas, a exemplo da norte-americana e de outros países anglo-saxônicos (Ehremberg e Smith, 1983), como em economias menos desenvolvidas, do tipo latino-americanas. Veja-se, por exemplo, o parágrafo de um artigo sobre a economia brasileira: "A correspondência entre o sugerido pelo instrumental teórico da política de estabilização e a experiência brasileira pós 1963 é claro demais para ignorar suas várias liçōes" (Contador, 1980).

O autor refere-se, nestas linhas, à curva de Phillips para o Brasil, 
deixando à parte, totalmente, as hipóteses utilizadas na sua construçāo teórica, suas limitaçōes e, o que é mais grave, as especificidades da economia brasileira, admitindo, desta maneira, a universalidade do instrumento, inclusive como elemento-chave para tomadas de decisões políticas.

Sabe-se que os processos de formação dos preços e salários no Brasil e em outros paises latino-americanos se distanciam muito daquele implícito no modelo de Phillips. O mercado de trabalho é heterogêneo e, no processo de formação dos salários, outros aspectos encontram-se muito mais atuantes do que os das livres forças de mercado.

A análise da inflação brasileira, baseada neste instrumento, conduz a uma visão parcial do problema, e as conseqüências das políticas que nele se apóiam são lamentáveis, para não dizer desastrosas. 0 fracasso das medidas aintiinflacionárias ortodoxas torna-se evidente, notadamente nos paises subdesenvolvidos, o que conduziu ao consenso de que nos processos inflacionários crônicos e elevados desses paises, o elemento principal da inflação era o inercial, ou o autônomo (Frenkel, 1986). Esta constatação, relativamente recente, surgiu no final dos anos setenta e resultou de uma série de teorias da inflação inercial.

Tomando o caso brasileiro como exemplo, entre outros países latino-americanos, o que se percebia era o fato de que sempre que a inflação alcançava um novo patamar, o governo fazia um grande esforço para reduzi-la via políticas recessivas, como políticas de redução da demanda através de limites à expansão da moeda e dos cortes da despesa pública, mas não conseguia trazê-la para um nivel inferior ao patamar onde havia se estabilizado anteriormente. A inflação subia anualmente, assumindo um caráter repetitivo ou inercial. Uma vez alcançado determinado patamar, o esforço que se fazia no combate da inflação e o custo social da recessão era muito elevado para evitar explosão dos preços, porém, ele não era suficiente para evitar a elevaçāo do referido patamar. Isto vem demonstrar que existem outros fatores impulsionadores dos preços além daqueles de mercado.

Os economistas latino-americanos encontraram uma explicação para o fenômeno da "estagnação", que resultou das políticas ortodoxas até então aplicadas, à partir de uma' análise mais realista do mercado de trabalho dessas economias. Apesar da diversidade de estrutura e de comportamento das referidas economias, foi identificado um ele- 
mento comum na explicação dos salários, a partir de estudos realizados para a Argentina, Chile, Brasil, Colômbia e Costa Rica. Verificouse que, entre outras variáveis, a taxa de inflação passada apresentava maior poder explicativo das variações de taxa de salário nominal e preço (Frenkel, 1986).

Isto poderia conduzir à conclusão, enganosa, de que o modelo da curva e Phillips, que inclui esta componente, seria aplicável ao caso latino-americano. (Serrano, 1986) reuniu e discutiu cinco formas teóricas puras de interpretação do caráter inercial da inflação utilizada na literatura econômica brasileira, que serão a seguir relacionadas: a versão das expectativas racionais, a versão das expectativas adaptativas, a interpretação institucional, a versão dos salários relativos e a do conflito distributivo.

As duas primeiras versões incluem uma visão teórica mais convencional do comportamento dos salários, fundamentada nas expectativas que os agentes econômicos têm sobre o salário real e nas expectativas de preços. $O$ comportamento dos agentes varia segundo suas expectativas se conformem aos fatos, como foi colocado na seção anterior. Segundo o referido autor, "é possível conciliar o modelo monetarista das expectativas racionais com a idéia de uma inflação inercial se se supõe que: a) o Banco Central siga uma política monetária passiva; b) a velocidade de circulação da moeda se mantenha estável; e c) os agentes privados se dêem conta disso". Na segunda versão, a das expectativas adaptadas, ele identifica duas opões: uma mais neoclássica e outra keynesiana. Com relação a neoclássica, a suposição básica é a da existência de um hiato de produto mínimo, enquanto a keynesiana supōe concorrência imperfeita nos mercados de bens e de trabalho. Nos dois casos a componente da demanda se torna desprezivel e a inflaçāo acaba sendo guiada por expectativas, mas que não correspondem ao caso latino-americano, tendo em vista suas hipóteses e seus aspectos circunstanciais, principalmente no que se refere ao tratamento dos salários. Não é redundante relembrar que as versões das expectativas adaptativas (neoclássicas) e das expectativas racionais incluem uma teoria de salário substancialmente incompatível com a realidade do país aqui focalizado, tendo em vista que, nele, o mercado de trabalho não é concorrencial. No que se refere à versão keynesiana, o enfoque das expectativas também não corresponderia à nossa realidade, apesar de sutpor concorrência imperfeita, ou seja, a presença de sindicatos nos mercados de trabalho e de oligopólios nos mercados de 
bens. A questão é que ainda não é possivel falar-se em sindicatos fortes nos países latino-americanos, a ponto de responsabilizá-los pela rigidez de salários.

As três últimas interpretações da inflação inercial apresentadas (institucional, salários relativos e conflitos distributivos) relativamente àquelas acima discutidas, apresentam superioridade na explicação da inflação inercial brasileira, pois percebe-se, claramente, que o tratamento dado aos salários foge àquela interpretação tradicional e ressalta os aspectos característicos desta realidade. $O$ argumento da interpretação institucional é o de que os preços macroeconồmicos básicos, entre eles os salários, sobem por decreto pela inflação passada e que os demais preços acompanham tais elevações. A versão dos salários relativos argumenta que existe uma série de fatores institucionais, politicos e costumes tradicionais, atuantes no mercado de trabalho promovendo um comportamento não cooperativo por parte dos grupos de trabalhadores na defesa de seus salários relativos, com base na dessincronização dos reajustes e na existência de inflação no passado recente do sistema. Finalmente, a versão do conflito destributivo explica a inércia através de um impasse social entre lucros e salários. Usando as palavras do autor, a mecânica será a seguir descrita: "Admitindo que o salário real desejado (ou considerado necessário) pelos trabaIhadores seja maior que o salário real que os capitalistas querem pagar, inicia-se um processo inflacionário que faz com que, após a negociação de cada contrato de trabalho, as firmas remarquem seus preços e que os salários reais sejam gradativamente reduzidos até atingirem um valor globalmente compatível com o "mark-up" desejado pelas empresas. A rodada de reajustes se repete enquanto a incompatibilidade distributiva se mantiver estável. A inflação se perpetua no mesmo patamar enquanto houver estabilidade dos termos de conflito distributivo entre lucros e salários".

Na discussão do parárafo anterior sobre a inflação inercial brasileira, percebe-se que o elemento de incerteza foi totalmente substituido por aspectos legais, institucionais e de jogo de forças, mais importante na determinação dos salários de economias subdesenvolvidas. $O$ enfoque neokeynesiano dos salários, exposto na primeira seção, não reúne todas essas características, porém apresenta-se aberto à inserção de alguns aspectos que encontram-se implícitos nestas interpretações de inflação.

Para finalizar, é importante que se coloque um aspecto que foi 
apontado por Simonsen (1986): "monetarismo e inercialismo são teorias complementares e não concorrentes. (...) Nada impede que se juntem as duas teorias, usando a política monetária para brecar a inflação aeróbica e os controles de preços, salários e taxas de câmbio para segurar a anaeróbica. $O$ bom senso exige que se corte o oxigênio da inflação e que, ao mesmo tempo, se suprima o fôlego das altas anaeróbicas de preços, que pode ser desprezivel em processos inflacionários de um dígito anual, mas não em inflação de dois dígitos gordos ou mais".

Uma reflexão sobre os dois tipos de teorias, inercialista e monetarista, a que Simonsen se refere, é indispensável. É verdade que a inflação brasileira e a dos demais palses latino-americanos não se restringe ao componente inercial, isto é, a uma inflação de equilíbrio, tendo em vista a instabilidade dos preços relativos, porém é necessário precaução relativamente à escolha da teoria. Com respeito às teorias inercialistas, consistentes com a realidade dos paises subdesenvolvidos, é possível uma fácil escolha, porém o mesmo não acontece com as teorias monetaristas, que foram elaboradas, em sua maioria, para outras realidades empíricas. Elas trazem, subjacentes, interpretações do mercado de trabalho, baseadas em hipóteses insustentáveis, até mesmo para as economias que as inspiraram, e que transfere essas imperfeiçōes para as teorias de inflação.

\section{CONCLUSÕES}

O fato de a inflação não ter causa única e de diferir entre as diversas economias se, por um lado, conduziu a uma incessante busca de aproximar as teorias aos eventos reais, por outro lado, levou a lamentáveis equívocos do ponto de vista de políticas para combatê-la, especialmente nos países subdesenvolvidos.

Sob vários ângulos, este problema já foi examinado, porém, neste trabalho, chegou-se à conclusão que, tendo em vista o conteúdo irreal das teorias de salário, transferido aos modelos de inflação que as inclui, a hipótese colocada inicialmente foi confirmada: quanto mais realista for o enfoque dado aos salários, mais eficazes serão as políticas antiinflacionárias que se baseiam nos modelos de inflação que $o$ inclui. 


\section{REFERÊNCIAS BIBLIOGRÁFICAS}

APPELBAUM, Eileen. The Labor Market in Post-Keynesian Theory; in: PIORE, Michael (ed.) Unemployment and Inflation - Institutionalist and Structuralist Views. USA, 1979.

BARBOSA, Fernando de Holanda. A Inflação Brasileira no PósGuerra: Monetarismo versus Estruturalismo, Rio de Janeiro, PNPE/IPEA, 1983.

CONTADOR, Cláudio Roberto. Recessão ou Inflação: as Faces do Debate. Conjuntura Econômica. Rio de Janeiro. 34(8):91-95; agosto, 1980.

EHREMBERG, Ronald G. e SMITH, Robert S. Modern Labor Economics: Theory and Public Policy, Illinois: Scott, Foresman and Company, 1983.

FRENKEL, Roberto. Salário e Inflação na América Latina: Resultados de Pesquisas Recentes na Argentina, Brasil, Chile, Colombia e Costa Rica Pesquisa e Planejamento Econômico, Rio de Janeiro, 16(1): 21-60, abril, 1986.

HUDSON, John. Inflation: a Theoretical Survey and Synthesis. London, George Allen \& Unwin. 1983.

KEYNES, J.M. A Teoria Geral do Emprego, do Juro e da Moeda. São Paulo. Atlas, 1982.

LASA, Alcides José. La Neutralidad de la Política Económica en los Modelos de Expectativas Racionales. El Trimestre Económico. México.

MACEDO, Roberto. Os Salários na Teoria Econômica. Rio de Janeiro, IPEA/INPES, 1982 (série PNPE, 2).

MADDOCK R. \& CARTER, M. A Child's Cuide to Rational Expectations. Journal of Economic Literature, vol. xx (March, 1982), p. 3951.

REGO, José Márcio et alii. Teorias Sobre Inflação: Uma Abordagem Introdutória. in:___ Inflação Inercial, Teorias Sobre Inflação e o Plano Cruzado. Rio de Janeiro, Paz e Terra, 1986.

SERRANO, Franklin Leon Peres. Inflação Inercial e Desindexação 
Neutra. in: REGO, J.M. et alii. Inflação Inercial, Teorias e o Plano Cruzado, Rio de Janeiro, Paz e Terra, 1986.

SILVA, Adroaldo Moura da. "Salários nos Modelos Macroeconômicos" Pesquisa e Planejamento Econômico, Rio de Janeiro, 8(1), abril, 1978.

SIMONSEN, Mário Henrique. Experiências Antiinflacionárias: Lições da História. In: REGO, J.M. et alii. Inflação Inercial, Teorias Sobre Inflação e o Plano Cruzado. Rio de Janeiro, Paz e Terra, 1986.

TREVITHICK, James A. \& MULVER, Charles. The Economics of Inflation. London, Martin Robertson \& Co., 1979. 